\title{
Ten-year outcome of intraoperative treatment of atrial fibrillation using radiofrequency ablation
}

\author{
This article was published in the following Dove Press journal: \\ Therapeutics and Clinical Risk Management \\ 19 September 2017 \\ Number of times this article has been viewed
}

\author{
Nour Boulad' \\ Nicolas W Shammas' \\ Gerald Early² \\ Shauna Roberts ${ }^{3}$ \\ Gail A Shammas' \\ Yuhning Linda $\mathrm{Hu}^{\prime}$ \\ Holly Park' \\ Michael Jerin' \\ 'Midwest Cardiovascular Research \\ Foundation, Bettendorf, IA, ${ }^{2}$ Cardiac \\ and Thoracic Surgery, Pullman \\ Hospital, Pullman, WA, ${ }^{3}$ Truman \\ Medical Center-Hospital Hill, Kansas \\ City, MO, USA
}

\begin{abstract}
Background: Intraoperative radiofrequency ablation (RFA) has been advocated to treat atrial fibrillation (AF). This report examines the long-term effects of intraoperative RFA in the prevention of recurrence of AF when used as an adjunctive treatment in patients undergoing cardiac procedures for primary indications unrelated to their arrhythmia.

Methods: The study reviewed the records of patients from a tertiary medical center which had 2 cardiac surgeons performing an intraoperative adjunctive RFA procedure. A total of 20 patients undergoing RFA between April 11, 2003 and May 10, 2005 were included and followed for up to 10 years. The primary effectiveness outcome of the study was the recurrence of AF during the follow-up period. Data were collected from office or hospital medical records.

Results: A total of 20 patients were included (mean age 69.4 years, males $40 \%$ ). Eight patients were followed for 10 years and 2 patients for 9 years; 7 patients died during the 10-year follow-up period and 3 patients were lost to follow-up. As their primary procedures, the patients underwent valve surgery (65\%), bypass surgery (15\%), or both (20\%). Intraoperative RFA failed to restore sinus rhythm in 2 patients. In the remaining 18 patients, $A F$ recurred in 10 patients within 2 months of surgery, in 1 patient at 5 months, in 1 patient at 7 months, and in 6 patients after 1 year.

Conclusion: AF had recurred in $100 \%$ of patients by the end of the long-term follow-up period. The adjunctive intraoperative RFA and postoperative interventions employed in this early study failed to maintain sinus rhythm.
\end{abstract}

Keywords: radiofrequency ablation, cardiac surgery, intraoperative, long-term outcome

\section{Introduction}

Atrial fibrillation (AF) is a relatively common irregular heart rhythm, affecting $\sim 2 \%$ of patients younger than 65 years and up to $9 \%$ of older patients. An estimated 2.7-6.1 million people have AF. ${ }^{1}$ Patients with AF have five times the incidence of strokes compared to patients with no $\mathrm{AF}^{2}$ and $\mathrm{AF}$ is responsible for $15 \%-20 \%$ of ischemic strokes, a significant health care burden. Although the treatment of AF frequently consists of either rate control or pharmacological antiarrhythmic therapies along with anticoagulation, percutaneous ablation strategies have been attempted in patients who remain symptomatic. Ablation therapies have been performed in patients with AF undergoing cardiac surgery; however, long-term data on the use of intraoperative radiofrequency ablation (RFA) are limited. This study analyzes the 10-year outcomes of intraoperative RFA in preventing the recurrence of $A F$ in the initial patients to whom we applied what was, at the time, a new technique.

\section{Patients and methods}

This is a retrospective study of 20 patients with a history of congestive heart failure and mixed valvular and coronary artery disease, plus concomitant AF who underwent
Correspondence: Nicolas W Shammas Midwest Cardiovascular Research Foundation, I622 E Lombard Street Davenport, IA 52803, USA

Email shammas@mchsi.com 
intraoperative RFA between April 11, 2003, and May 10, 2005, at a tertiary medical center. This study was approved by the Genesis Health System Institutional Review Board. Consent was waived as there was no direct patient contact required by investigators and all data were collected from medical records. Also, all investigators have signed a Health Insurance Portability and Accountability Act agreement to maintain the confidentiality of medical records. The Synergy Atri-Cure Radiofrequency clamp (AtriCure, West Chester, OH, USA) was used to mimic portions of the cut-and-sew lesions of the Cox-maze procedure. Nine patients received a limited intervention of pulmonary vein isolation (with left atrial appendage excision in 7 patients). The remainder had a more complex set of ablative lesions.

The limited intervention lines of RFA were two encircling lesions that isolated the paired right and left pulmonary veins (PVs). These two lines of ablation were applied to all patients and were done following the manufacturer's recommendation to "fire" the device twice on each side after passing the externally applied clamp cranially to caudally and then caudally to cranially (refer to figure 3 of Gillanov and $\mathrm{McCarthy}^{3}$ ). Eleven patients had a more complex procedure with additional lesions consistent with the left atrial (only) lesions recently shown in figure $2 \mathrm{~A}$ of the ABLATE Trial report. ${ }^{4}$ In addition to the encircling lesions, a third line of ablation connected the caudal portions of the right and left PVs encircling lesions; the fourth line connected the cranial portion of the right and left PVs encircling lesions; the fifth lesion went from the left superior pulmonary vein to the left atrial appendage excision; and a sixth lesion was done with a cryoprobe to create a line of ablation from the caudal portion of the right PVs encircling lesion to the mitral valve annulus. The left atrial appendage was excised in the majority of patients, and additional right atrial lesions were created in three patients.

All patients were seen by their surgeon at 2-4 weeks postdischarge from the hospital for short-term follow-up, but the ongoing follow-up and antiarrhythmic therapy was less structured, more variable, and did not always include an electrophysiologist.

Recurrence of AF was evaluated from medical records by reviewing electrocardiograms during outpatient or hospitalization visits or from Holter and/or 30-day event care monitor reports when available. Follow-up was censored at 10 years or when AF recurrence was documented. AF was classified as paroxysmal (terminates spontaneously within 7 days of occurrence), persistent (sustained beyond 7 days but responds to pharmacological or electric cardioversion), or permanent (continuous and does not respond to intervention or patient and provider have agreed on no further treatment). Variables collected from records included age, gender, type of surgery (valve, bypass, or combination), body mass index, left ventricular ejection fraction, left atrial size, creatinine, intraoperative atrial appendage excision, history of hypertension, hyperlipidemia, diabetes mellitus, smoking, stroke, carotid artery disease, and peripheral arterial disease. Outcome variables included the number of days for AF recurrence, recurrence of $\mathrm{AF}$, death, myocardial infarction, and stroke.

Descriptive analysis was performed on all variables. Dichotomous variables were described as percentages and continuous variables as mean \pm SD. Freedom from recurrence of AF was plotted using Kaplan-Meier curve censored to 10 years or death (SPSS; IBM Corporation, Armonk, NY, USA).

\section{Results}

The original cohort consisted of 24 patients. In 4 patients, postoperative and follow-up records were not available, and they were excluded from further analysis. In the remaining 20 patients, the mean age was $69.4 \pm 9.5$ years (range $48-88$ years) and $40 \%$ were males. Of the 20 patients, $10(50 \%)$ had persistent AF, 4 (20\%) had permanent AF, and $6(30 \%)$ had paroxysmal AF. Table 1 describes patients' clinical and echocardiographic characteristics. Notably, left atrial size was $5.0 \pm 0.7 \mathrm{~cm}$ and left ventricular ejection fraction was $46.3 \% \pm 14.0 \%$. Diabetes was present in $25 \%$ of patients and coronary artery disease in $45 \%$. Surgical procedures performed included single or multiple valve procedures, including repairs and replacements in 65\%, coronary artery bypass surgery with at least one internal mammary graft in $15 \%$, and both valvular and coronary bypass surgery with at least one internal mammary artery graft in $20 \%$ of patients. Left atrial appendage excision or exclusion was performed in $85 \%$ of patients. The left atrial appendage was not amenable to excision in one patient due to dense adhesions, failed in one patient due to stapler malfunction, and left atrial excision was not described in the operative dictation in the third patient. Right atrial ablation procedures were added in three patients. All patients were placed on oral anticoagulants postoperatively.

Table 2 describes postoperative outcomes. There were no major complications related to the adjunctive antiarrhythmic procedures. No strokes or other thromboembolic events occurred, and the in-hospital and 30-day mortality was 0 . Eight patients were followed for 10 years and two patients for 9 years. Seven patients died during the 10-year follow-up and 3 patients were lost to follow-up. In 2 patients, intraoperative RFA failed to maintain sinus rhythm prior to discharge. 
Table I Descriptive analysis

\begin{tabular}{|c|c|c|c|}
\hline Baseline variables & $\mathbf{n}$ & Mean \pm SD & \\
\hline Age (years) & 20 & $69.4 \pm 9.5$ & \\
\hline Body mass index $\left(\mathrm{kg} / \mathrm{m}^{2}\right)$ & 20 & $28.6 \pm 6.8$ & \\
\hline Ejection fraction (\%) & 20 & $47.1 \pm 13.1$ & \\
\hline $\begin{array}{l}\text { Left atrial size measured by } \\
\text { echocardiography }(\mathrm{cm})\end{array}$ & 17 & $5.0 \pm 0.7$ & \\
\hline \multirow[t]{2}{*}{ Baseline creatinine $(\mathrm{mg} / \mathrm{dL})$} & 20 & $1.2 \pm 0.4$ & \\
\hline & $\mathbf{n}$ & $\mathbf{n}^{\prime}$ & Percentage \\
\hline Males & 20 & 8 & 40 \\
\hline Type of AF & 20 & & \\
\hline Permanent & & 4 & 20 \\
\hline Paroxysmal & & 6 & 30 \\
\hline Persistent & & 10 & 50 \\
\hline Hypertension & 20 & 13 & 65 \\
\hline Hyperlipidemia & 20 & 16 & 80 \\
\hline Coronary artery disease & 20 & 9 & 45 \\
\hline Diabetes mellitus & 20 & 5 & 25 \\
\hline History of smoking & 19 & 8 & 42 \\
\hline History of stroke & 20 & 0 & 0 \\
\hline Peripheral arterial disease & 20 & 5 & 25 \\
\hline Carotid artery disease & 20 & 2 & 10 \\
\hline NYHA heart failure class & 5 & & \\
\hline 2 & & 2 & 40 \\
\hline 3 & & 2 & 40 \\
\hline 4 & & I & 20 \\
\hline \multicolumn{4}{|l|}{ Preoperative medications } \\
\hline Digoxin & 20 & 10 & 50 \\
\hline Beta blocker & 20 & 20 & 100 \\
\hline $\begin{array}{l}\text { Angiotensin-converting } \\
\text { inhibitor }\end{array}$ & 20 & 15 & 75 \\
\hline Angiotensin receptor & 20 & 3 & 15 \\
\hline \multicolumn{4}{|l|}{ blocker } \\
\hline Diuretics & 20 & 17 & 85 \\
\hline Statin & 20 & 8 & 40 \\
\hline ASA & 20 & 12 & 60 \\
\hline Calcium channel blockers & 20 & 3 & 15 \\
\hline Clopidogrel & 20 & 2 & 10 \\
\hline Nitrate & 20 & 4 & 20 \\
\hline Warfarin & 20 & 19 & 95 \\
\hline \multicolumn{4}{|l|}{ Intraoperative variables } \\
\hline $\begin{array}{l}\text { Left atrial appendage excision } \\
\text { or ligation surgically }\end{array}$ & 20 & 17 & 85 \\
\hline Type of surgery & 20 & & \\
\hline Valve only & & 13 & 65 \\
\hline Bypass surgery only & & 3 & 15 \\
\hline Both valve and bypass & & 4 & 20 \\
\hline $\begin{array}{l}\text { Maze procedure in addition } \\
\text { to ablation }\end{array}$ & 20 & 3 & 15 \\
\hline
\end{tabular}

Abbreviations: AF, atrial fibrillation; ASA, aspirin; $n$, total number of patients; $n^{\prime}$, number of patients in each variable; NYHC, New York Heart Class.

In the remaining 18 patients, $\mathrm{AF}$ recurred in 10 patients within 2 months of surgery, in 1 patient at 5 months, in 1 patient at 7 months, and in 6 patients after 1 year. Figure 1 illustrates freedom from AF over the 10 years of follow-up. Postoperative AF was permanent in $30 \%$ of patients, persistent in $65 \%$, and paroxysmal in $5 \%$. Percutaneous catheter
Table 2 Postoperative outcomes

\begin{tabular}{|c|c|c|c|}
\hline & $\mathbf{n}$ & $\mathbf{n}^{\prime}$ & Percentage \\
\hline Type of AF on follow-up & 20 & & \\
\hline Paroxysmal & & I & 5 \\
\hline Persistent & & 13 & 65 \\
\hline Permanent & & 6 & 30 \\
\hline Antiarrhythmic drug use & 20 & & \\
\hline None & & 3 & 15 \\
\hline On the drugs at the time of recurrence of $\mathrm{AF}$ & & 11 & 55 \\
\hline Started drugs after recurrence of $A F$ & & 6 & 30 \\
\hline Repeat RF ablation & 20 & 4 & 20 \\
\hline $\begin{array}{l}\text { Occurrence of stroke after successful } \\
\text { ablation }\end{array}$ & 20 & 0 & 0 \\
\hline Use of anticoagulant postoperatively & 20 & 20 & 100 \\
\hline Warfarin & 20 & 12 & 60 \\
\hline ASA & 20 & 12 & 60 \\
\hline Plavix & 20 & 1 & 5 \\
\hline Cardioversion attempt & 20 & 17 & 85 \\
\hline Ventricular arrhythmias & 20 & 3 & 15 \\
\hline Syncope & 20 & 3 & 15 \\
\hline Stroke & 20 & 2 & 10 \\
\hline MI during follow-up period & 20 & 3 & 15 \\
\hline Use of ICD/pacer in follow-up period & 20 & 12 & 60 \\
\hline Development of postpericardiotomy syndrome & 20 & 2 & 10 \\
\hline $\begin{array}{l}\text { Development of renal failure on follow-up } \\
\text { requiring dialysis }\end{array}$ & 20 & I & 5 \\
\hline Need for revision surgery & 20 & 0 & 0 \\
\hline Need for percutaneous coronary intervention & 20 & 7 & 35 \\
\hline
\end{tabular}

Abbreviations: AF, atrial fibrillation; ASA, aspirin; ICD, implantable cardioverter defibrillator; MI, myocardial infarction; $n$, total number of patients; $n^{\prime}$, number of patients in each variable; RF, radiofrequency.

ablation was done in $20 \%$ of patients during the follow-up period and $12(60 \%)$ required a pacemaker.

Using multivariate analysis modeling for age, hypertension, diabetes, type of $\mathrm{AF}$, and ejection fraction, independent factors that predict recurrence of $\mathrm{AF}$ in the postoperative period could not be identified.

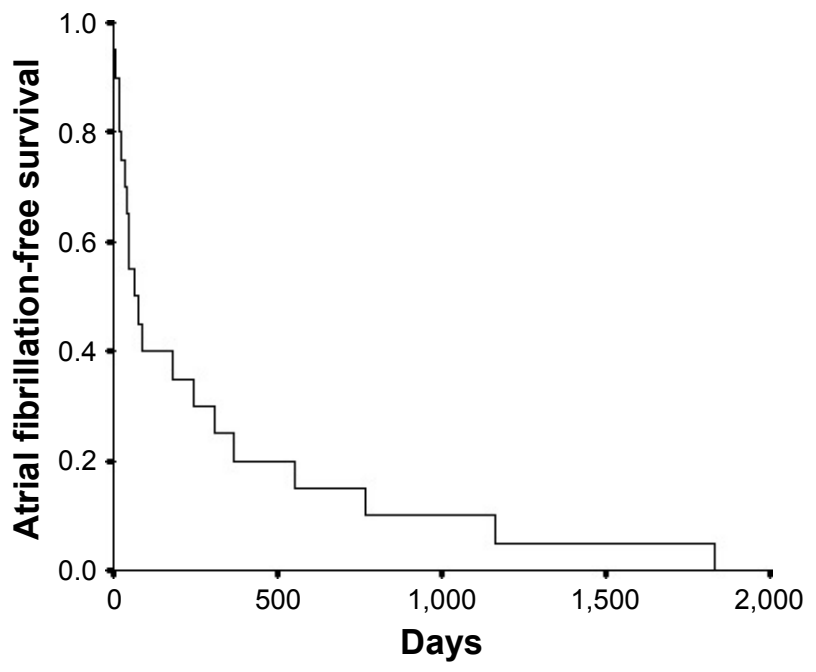

Figure I Kaplan-Meier plot illustrating freedom from atrial fibrillation on 10-year follow-up after intraoperative radiofrequency ablation. 


\section{Comment}

Catheter ablation (RF or cryoablation) is generally reserved for symptomatic AF patients who have failed at least one (class I or III) antiarrhythmic therapy when rhythm control strategy is desired (1). Since the PVs have been identified as an important trigger of AF, PV isolation has become the target for both successful catheter and surgical AF ablation., 5 Targets of catheter RFA have aimed for focal triggers or local reentries at the PV ostia for paroxysmal AF (wide antral circumferential ablation), whereas for persistent AF catheter, RFA has centered on PVs, atrial myocardium (substrate modification) with linear lesions, complex fractionated atrial electrograms, rotors or focal sources, left atrium low-voltage areas, sites of high dominant frequency, and ganglionic plexi (GP)..$^{7-15}$ Epicardial GP and the ligament of Marshall (LoM) have also been shown to trigger AF PV ectopy, leading to multiple variants on the surgical Maze procedure. The data on long-term durability regarding the contribution of GP and LoM mapping and ablation compared to PV isolation have been minimal. ${ }^{16-19}$ The ongoing Catheter Ablation vs Antiarrhythmic Drug Therapy for Atrial Fibrillation trial (CABANA) will report whether pulmonary vein isolation catheter ablation versus either rate or rhythm control by medical therapy is superior for the elimination of AF or whether catheter ablation decreases 5-year outcomes of mortality, disabling stroke, bleeding, or cardiac arrest in AF patients (Douglas Packer; Mayo Clinic; https://ClinicalTrials.gov/ct2/show/NCT00911508).

In one long-term study that followed patients for 6 years, the recurrence rate was $>50 \% .{ }^{20}$ Also real-world data indicated that the rate of AF recurrence was as high as $60 \%$ at 1 -year follow-up and repeat ablation ranged from $10 \%$ to $18 \%$ during the same period. ${ }^{21}$ Several studies have shown that surgical ablation is superior to catheter ablation in maintaining sinus rhythm, but overall these studies have been limited to short-term follow-up. ${ }^{22-24}$ A report from Christchurch, New Zealand, on 44 patients treated with surgical RFA found that $93 \%$ of patients were in sinus rhythm in the immediate postoperative period, with a $7 \%$ mortality rate prior to discharge and an $82 \%$ arrhythmia recurrence on follow-up that extended out to 102 months. ${ }^{25}$ A more complex procedure that includes converging endocardial and epicardial lesions coupled with aggressive repeat catheter ablation when needed has recently been shown to yield improved results with $81 \%$ of patients in sinus rhythm at 4 years of follow-up. ${ }^{26}$ Beukema et $\mathrm{al}^{27}$ reported that $68 \%$ of patients treated with epicardial RFA for isolated AF had recurrence of the arrhythmia, but they were able to maintain a sinus rhythm with additive catheter ablation in $87 \%$ of those who underwent reintervention.
In this study, we show a time-dependent recurrence of AF in patients who underwent intraoperative RF ablation as we applied it early in our experience. All patients had recurrence at 10 years after their procedure and recurrence of $\mathrm{AF}$ was not controlled in the 4 patients who had repeat catheter ablation. However, these data may not apply to other intraoperative techniques to treat $\mathrm{AF}$.

\section{Conclusion}

Although sinus rhythm in the immediate postoperative period may have had positive impact on the ability to separate these patients from cardiopulmonary bypass and might have contributed to their early survival, AF had recurred in $100 \%$ of patients by the time of the long-term follow-up. The majority of patients had early recurrence within 1 year of their procedure, and repeat catheter ablation, when applied, was not helpful in maintaining sinus rhythm. No independent predictors of AF recurrence were identified.

The $100 \%$ recurrence of AF leads to the conclusion that our practice was not effective in maintaining long-term sinus rhythm in this group of congestive heart failure patients. This study is limited by the small number of patients, the variability of ablative lesions and LAA excision, and the missed opportunity for a scripted and coordinated follow-up plan. More extensive ablative procedures, focused follow-up that includes a cardiologist and an aggressive approach that includes pharmacological and electrophysiological intervention for arrhythmia recurrence, would be expected to yield improved long-term results.

\section{Disclosure}

The authors report no conflicts of interest in this work.

\section{References}

1. January CT, Wann LS, Alpert JS, et al. 2014 AHA/ACC/HRS guideline for the management of patients with atrial fibrillation. J Am Coll Cardiol. 2014;64(21):2246-2280.

2. Mozaffarian D, Benjamin EJ, Go AS, et al. Heart disease and stroke statistics - 2015 update: a report from the American Heart Association. Circulation. 2015;131(4):e29-e322.

3. Gillanov AM, McCarthy PM. Atricure bipolar radiofrequency clamp for intraoperative ablation of atrial fibrillation. Ann Thorac Surg. 2002; 74(6):2165-2168.

4. Philpott JM, Zemlin CW, Cox JL, et al. The ABLATE Trial: safety and efficacy of Cox Maze-IV using a bipolar radiofrequency ablation system. Ann Thorac Surg. 2015;100(5):1541-1546.

5. Haïssaguerre M, Jaïs P, Shah DC, et al. Spontaneous initiation of atrial fibrillation by ectopic beats originating in the pulmonary veins. $N \mathrm{Engl}$ J Med. 1998;339(10):659-666.

6. Jaïs P, Cauchemez B, Macle L, et al. Catheter ablation versus antiarrhythmic drugs for atrial fibrillation: the A4 study. Circulation. 2008; 118(24):2498-2505.

7. Iwasaki YK, Nishida K, Kato T, Nattel S. Atrial fibrillation pathophysiology: implications for management. Circulation. 2011;124(20): 2264-2274. 
8. Haïssaguerre M, Hocini M, Sanders P, et al. Catheter ablation of longlasting persistent atrial fibrillation: clinical outcome and mechanisms of subsequent arrhythmias. J Cardiovasc Electrophysiol. 2005;16(11): $1138-1147$.

9. Willems S, Klemm H, Rostock T, et al. Substrate modification combined with pulmonary vein isolation improves outcome of catheter ablation in patients with persistent atrial fibrillation: a prospective randomized comparison. Eur Heart J. 2006;27(23):2871-2878.

10. Narayan SM, Krummen DE, Shivkumar K, Clopton P, Rappel WJ, Miller JM. Treatment of atrial fibrillation by the ablation of localized sources: CONFIRM (Conventional Ablation for Atrial Fibrillation with or without Focal Impulse and Rotor Modulation) trial. J Am Coll Cardiol. 2012;60(7):628-636.

11. Hayward RM, Upadhyay GA, Mela T, et al. Pulmonary vein isolation with complex fractionated atrial electrogram ablation for paroxysmal and nonparoxysmal atrial fibrillation: a meta-analysis. Heart Rhythm. 2011;8(7):994-1000.

12. Atienza F, Almendral J, Jalife J, et al. Real-time dominant frequency mapping and ablation of dominant frequency sites in atrial fibrillation with left-to-right frequency gradients predicts long-term maintenance of sinus rhythm. Heart Rhythm. 2009;6(1):33-40.

13. Pokushalov E, Romanov A, Artyomenko S, et al. Ganglionated plexi ablation for longstanding persistent atrial fibrillation. Europace. 2010; 12(3):342-346.

14. Narayan SM, Baykaner T, Clopton P, et al. Ablation of rotor and focal sources reduces late recurrence of atrial fibrillation compared with trigger ablation alone: extended follow-up of the CONFIRM trial (conventional ablation for atrial fibrillation with or without focal impulse and rotor modulation). J Am Coll Cardiol. 2014;63(17):1761-1768.

15. Baykaner T, Lalani GG, Schricker A, Krummen DE, Narayan SM. Mapping and ablating stable sources for atrial fibrillation: summary of the literature on Focal Impulse and Rotor Modulation (FIRM). J Interv Card Electrophysiol. 2014;40(3):237-244.

16. Zheng S, Li Y, Han J, et al. Long-term results of a minimally invasive surgical pulmonary vein isolation and ganglionic plexi ablation for atrial fibrillation. PLoS One. 2013;8(11):e79755.

17. Zheng S, Zeng Y, Li Y, Han J, Zhang H, Meng X. Active ganglionated plexi is a predictor of atrial fibrillation recurrence after minimally invasive surgical ablation. J Card Surg. 2014;29(2):279-285.
18. Szalay ZA, Civelek A, Dill T, Klövekorn WP, Kilb I, Bauer EP. Longterm follow-up after the mini-maze procedure. Ann Thorac Surg. 2004; 77(4):1277-1281.

19. Janusauskas V, Puodziukaite L, Maneikiene VV, et al. Long-term results of minimally invasive stand-alone bi-atrial surgical ablation with a bipolar ablation device for persistent and longstanding persistent AF: a single-center case series of 91 patients. J Cardiothorac Surg. 2016;11:23

20. Boveda S, Providência R, Defaye P, et al. Outcomes after cryoballoon or radiofrequency ablation for persistent atrial fibrillation: a multicentric propensity-score matched study. J Interv Card Electrophysiol. 2016;47:133-142.

21. Ha AC, Wijeysundera HC, Birnie DH, Verma A. Real-world outcomes, complications, and cost of catheter-based ablation for atrial fibrillation: an update. Curr Opin Cardiol. 2017;32(1):47-52.

22. Boersma LV, Castella M, van Boven W, et al. Atrial fibrillation catheter ablation versus surgical ablation treatment (FAST): a 2-center randomized clinical trial. Circulation. 2012;125(1):23-30.

23. Pokushalov E, Romanov A, Elesin D, et al. Catheter versus surgical ablation of atrial fibrillation after a failed initial pulmonary vein isolation procedure: a randomized controlled trial. J Cardiovasc Electrophysiol. 2013;24(12):1338-1343.

24. Kearney K, Stephenson R, Phan K, Chan WY, Huang MY, Yan TD. A systematic review of surgical ablation versus catheter ablation for atrial fibrillation. Ann Cardiothorac Surg. 2014;3(1):15-29.

25. Coolbear F, Crozier IG. Surgical radiofrequency ablation for atrial fibrillation: the Christchurch, New Zealand experience. $N$ Z Med J. 2011; 124(1343):33-38

26. Gersak B, Jan M. Long-term success for the convergent atrial fibrillation procedure: 4-year outcomes. Ann Thorac Surg. 2016;102(5): 1550-1557.

27. Beukema RJ, Adiyaman A, Smit JJJ, Delnoy PPHM, Misier ARR, Elvan A. Catheter ablation of symptomatic postoperative atrial arrhythmias after epicardial surgical disconnection of the pulmonary veins and left atrial appendage ligation in patients with atrial fibrillation. Eur J Cardiothorac Surg. 2016;49(1):265-271.
Therapeutics and Clinical Risk Management

\section{Publish your work in this journal}

Therapeutics and Clinical Risk Management is an international, peerreviewed journal of clinical therapeutics and risk management, focusing on concise rapid reporting of clinical studies in all therapeutic areas outcomes, safety, and programs for the effective, safe, and sustained use of medicines. This journal is indexed on PubMed Central, CAS,

\section{Dovepress}

EMBase, Scopus and the Elsevier Bibliographic databases. The manuscript management system is completely online and includes a very quick and fair peer-review system, which is all easy to use. Visit http://www.dovepress.com/testimonials.php to read real quotes from published authors. 